\title{
Obituaries
}

\section{Major David Eilenberg, MB BS Lond Univ, FRCP, FRCPsych, DPM, MRANZCP, FRANZCP}

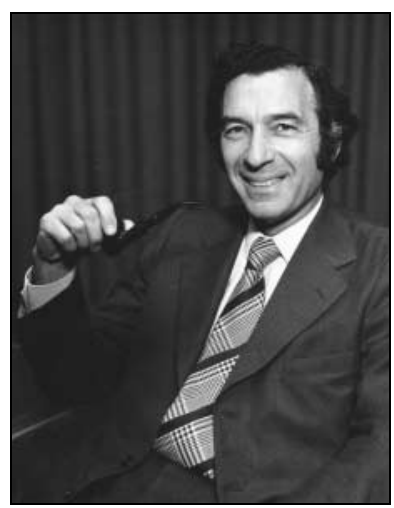

Formerly consultant psychiatrist at Wembley, Shenley and Northwick Park Hospitals, UK, Director of the Division of Psychiatry at Auckland Hospital, New Zealand

Eilenberg was an exceptionally able clinician with administrative ability and an intense interest in medical ethics. He seemed the right man for the psychiatric services at Northwick Park Hospital and their liaison with the Medical Research Council's Clinical Research Centre when it opened in 1970. However, New Zealand attracted him more and he completed a successful career in Auckland, where he migrated in 1975.

Eilenberg was born in 1925 at Pitsea, Essex, the older of the two children of Sidney Eilenberg, a confectioner, and Annie Eilenberg, née Shube. Sidney Eilenberg came to England from Poland in 1915. His wife and her parents had arrived from Poland some years earlier. Major, a name deliberatively chosen by his father for its distinctiveness and which caused life-long confusion with the military rank, was educated at Hackney Downs School, a London County Council grammar school, formerly the Grocer's Company's School. The School's alumni include Steven Berkoff, John Bloom, Michael Caine, Arnold Goodman and Harold Pinter, among many other notable men.

Eilenberg graduated MB BS (London) in 1948 from the London Hospital Medical School. After house officer appointments at the London Hospital, Eilenberg completed his National Service (1953-1955) in the Medical Branch of the Royal Air Force, serving in the Middle East with the rank of squadron leader. He then became registrar and senior registrar (1955-1961) at the Maudsley Hospital. The Maudsley was then the world's leading postgraduate school of psychiatry.

Eilenberg flourished. He published, as author or co-author, ten papers based on research conducted during his training, a remarkable achievement for a junior doctor. Notable were two papers, one a study of 1200 emergency psychiatric admissions over 1 year to St Francis' Hospital Mental Observation Unit and the other a comparison of 1930 and 1955 admissions to Stamford House, a boys' remand centre. Prominent in both are his interest in medical aspects of psychiatry and in the importance of administration in providing healthcare.

In 1956, showing an independence of thought, Eilenberg, a secular Jew, convened a meeting of fellow junior doctors where he proposed a motion of no confidence in Prime Minister Eden's conduct of the Suez Crisis. The motion was carried and the news conveyed to Downing Street.
To broaden his experience Eilenberg spent 1961-1962 at the Mayo Clinic as a staff psychiatrist. From here he published three papers, one on liaison psychiatry which showed his developing interest in this specialty. He joined the Mayo Clinic Chapter of Sigma $\mathrm{Xi}$, a society dedicated to promoting integrity in science and engineering.

Eilenberg returned to England to be consultant psychiatrist at Wembley Hospital (1963-1970) and then Shenley and Northwick Park Hospitals (1970-1974). Northwick Park Hospital was established in 1970 jointly by the Medical Research Council (MRC) and the National Health Service (NHS) to provide for clinical research. Here Eilenberg became a key figure in establishing the new NHS psychiatric service and ensuring its cooperation with the MRC Clinical Research Centre where T. J. Crow was appointed head of the division of psychiatry.

Such was Eilenberg's stature that he became chairman of the Ethical Committee for Northwick Park Hospital, a committee which played a key role in facilitating clinical research across all disciplines. A BMJ-sponsored discussion on the ethics of clinical research between L. J. Witts, Nuffield Professor of Medicine at Oxford, R. Williams, director of liver research at King's College Hospital and Eilenberg, shows Eilenberg's grasp of the principle issues. Essentially, he argued for promoting a culture of ethical concern among all professions involved in clinical research.

In 1974, to the astonishment of his colleagues, Eilenberg said he and his family were moving to Auckland, New Zealand, as he put it, 'to go back 50 years in time'. He became Director of the Division of Psychiatry at Auckland Hospital in 1975. His superior clinical ability, grasp of medical administration and mentorship of younger men were appreciated. And his advice on psychiatric aspects of medical and especially neurological illness was sought after. He retired from his hospital post in 1985 to work part time in the Geriatric Unit at Auckland Hospital as a valued liaison psychiatrist until 2002. He also had a private consulting practice at the Bexley Clinic in Auckland where he continued until 2008.

He died in February 2012. After his death a colleague remarked: 'He made an enormous contribution to Auckland psychiatry in the formal training of young psychiatrists and as a role model for new consultants, encouraging participation in administration, service delivery and negotiation with management'.

Eilenberg's chief interest, outside his family, was golf, with a fairly average handicap. His regret was not to have come to Auckland 10 years earlier.

Eilenberg married in 1955 Elizabeth Joan Rothwell, a Senior Charge Nurse at the London Hospital and daughter of Frederick Rothwell, sometime Vicar of Denmead, Hants. He is survived by Elizabeth and their two sons, Richard, a dentist, and Philip, an accountant, both in Auckland. Their third child, Nigel, died in 2011.

Brian Barraclough brian.barraclough@xtra.co.nz

doi: $10.1192 /$ pb.bp. 113.043380 